\title{
Finite Element Analysis of Luffing Jib for Landing- Type Lifting Pole with Single Luffing Jib
}

\author{
J. Qin \\ China Electric Power Research Institute \\ Beijing, China \\ F.Y. Hu \\ China Electric Power Research Institute \\ Beijing, China \\ D. $\mathrm{Ni}$ \\ China Electric Power Research Institute \\ Beijing, China
}

\begin{abstract}
The landing-type lifting pole with single luffing jib is researched and manufactured as a kind of construction equipment used in erection of large-sized iron tower in transmission line. The numerical calculation by finite element method was conducted aiming at luffing jib of landing-type lifting pole at different lifting positions and with different lifting loads. The structural stresses of luffing jib of landingtype lifting pole under the conditions of rated lifting torque, brake rotating status, wind perpendicular to jib, etc. were analysed. In addition, the check to materials of various parts of luffing jib and the entire structural strength was conducted based on the calculated results. The check results can be taken as reference for structural design of landing-type lifting pole.
\end{abstract}

Keywords-single luffing jib; landing-type lifting pole; structural analysis; finite element

\section{INTRODUCTION}

The landing-type lifting pole with single luffing jib (shown in Figure 1) SXD50 is researched and designed based on the construction tower crane, aiming at features and requirements of iron tower erection of UHV power transmission line, using and absorbing advantages of landing lifting pole with double flat arms (double rocking arms) and fully exerting lifting features and superiorities[1].

The landing-type lifting pole of single luffing jib is located in the center of iron tower, which is flexibly attached with iron tower, and it loads the tower materials through tilting and rotating of single luffing jib. Its maximum working height is $150 \mathrm{~m}$, with the maximum working amplitude of $20 \mathrm{~m}$, lifting load at the pointed end of $2.5 \mathrm{t}$ and the maximum lifting capacity of $4 \mathrm{t}$. When the iron tower construction is completed, the jib and balance arm can be closed together at the top of pole, so the body of pole can be dismantled within the top window of tower (about $3.4 \mathrm{~m} 2$ ). Therefore, it is a dedicated equipment very applicable to erection of iron tower.

\author{
Y.J. Hao \\ China Electric Power Research Institute \\ Beijing, China \\ J. Su \\ Shenyang Sanyo Building Machinery Co., Ltd, Shenyang, \\ China
}

\section{H.S. Zhang}

Harbin Institute of Technology Harbin, China

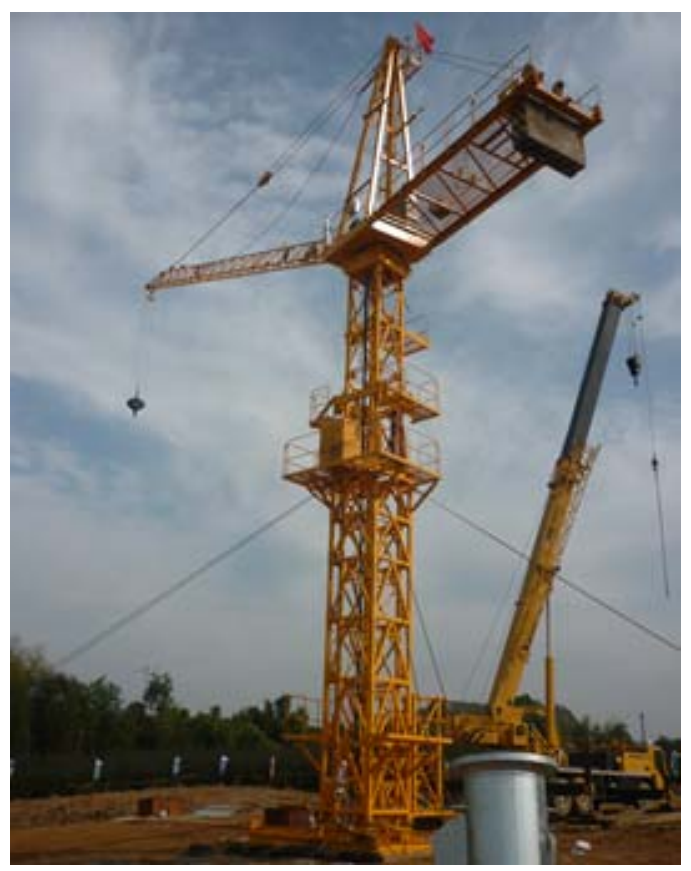

FIGURE I.LANDING-TYPE LIFTING POLE WITH SINGLE LUFFING JIB

The landing-type lifting pole with single luffing jib possesses features including simple force status, high spatial utilization and convenient rope-threading. During the construction, there is few required auxiliary work, the lifting members don't have to be arranged in symmetric way, and the site coverage is small [2]. Therefore, the jib design is important in the entire design of lifting pole.

\section{ESTABLISHMENT OF JIB MODEL OF LIFTING POLE}

The model establishment of jib (shown in Figure 2) should conform to the following principles: (1) The research 
object should be able to reflect features of deformation and stress of pole jib under working status completely and exactly. (2) The structural model of jib should keep geometric similarity with the actual shape, and the local structures which has no large influence on researched problems can be simplified appropriately. (3) The stress of pole jib should be consistent with actual externally applied load. (4) The boundary constraint conditions of jib model should conform to actual situations.

The sizes of luffing jib are shown in Table 1.

TABLE 1: THE CHARACTERISTIC OF LUFFING JIB.

\begin{tabular}{|l|l|l|}
\hline Project & Length $(\mathrm{mm}) \times$ Width $(\mathrm{mm}) \times$ Height $(\mathrm{mm})$ & Weight \\
\hline $\begin{array}{l}\text { Jib } \\
\text { assembly }\end{array}$ & $21140 \times 576 \times 776$ & 1385 \\
\hline $\begin{array}{l}\text { Root } \\
\text { section }\end{array}$ & $8017 \times 576 \times 776$ & 537 \\
\hline $\begin{array}{l}\text { Short } \\
\text { section }\end{array}$ & $5490 \times 576 \times 776$ & 255 \\
\hline $\begin{array}{l}\text { End } \\
\text { section }\end{array}$ & $7633 \times 576 \times 776$ & 465 \\
\hline
\end{tabular}

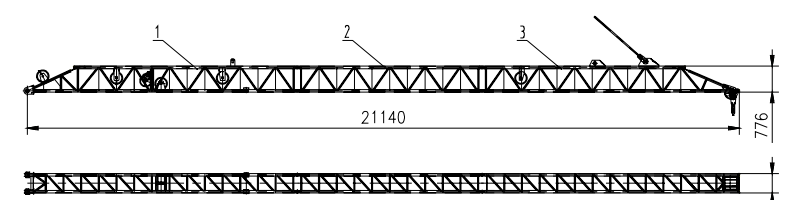

FIGURE II.

THE LUFFING JIB OF LANDING-TYPE LIFTING POLE

According to the above principles, the treatment should be conducted during the model establishment [3]: (1)The upper and lower chord members and web members are simulated by beam units, and the long and short draw-bars are simulated by bar units. (2) The cross-section of jib is reduced gradually from root to end, so the establishment of key points at joints of jib sections should be conducted according to the cross-section dimensions of the last section of jib. (3) The upper and lower chord members and web members of each jib section have the same density. (4) The roots of jib and draw-bar should be connected with hinged support at their corresponding positions.

\section{LOAD OF POLE JIB}

The loads of the pole jib include: dead weight load of jib, lifting capacity load, wind load, pressure load of lifting rope to jib, rotary inertial force and inertial force of trolley travel, with their calculation methods as below.

\section{A. Dead Weight Load of Jib}

In the ANSYS software, it is only necessary to add a gravitational acceleration when adding the dead weight load. Its dead weight load can be computed automatically by its internal operating program.

\section{B. Calculated Load of Lifting Capacity}

$$
G^{\prime}=\left(G+G_{\text {lifting group }}+G_{\text {rope }}\right) \times \varphi
$$

$$
\varphi=n \times 0.17 / 2+1.05
$$

Where: $G_{\text {lifting group }}-$ Dead weight of pulley group and lifting hooks: $0.2 \mathrm{t}$ ( 2 times)

$G_{\text {rope }}$ - Dead weight of lifting rope: $0.182 \mathrm{t}$ ( 2 times)

$G-$ Rated lifting weight (t)

$\varphi$ - Dynamic load factor

$n$ - Times lifting speed $(\mathrm{m} / \mathrm{s})$ under rated lifting load of lifting hooks and pulley group.

For the functional point of lifting capacity load is not on the node, the principle of virtual work should be applied to distribute $G$ ' to nodes where lifting hooks are located equivalently.

\section{Wind Load Fw of Jib}

$$
\mathrm{Fw}=\mathrm{Cw} \text { pw lhw }
$$

Where: $C_{w}-$ Wind force coefficient, with the lower chord value of 1.6 and other member values of 1.0.

$p_{w}$ - Calculated wind pressure, $250 \mathrm{~Pa}$.

$\omega$ - Structural saturation ratio, with front plate 1.0, and the rear plate 0.75 .

$l$ - Length of jib.

$h$-Cross-section height of jib.

The values of $C_{w}, p_{w}$ and $\omega$ should conform to GB/T 13752-92 Design Rules for Tower Cranes.

The applying of wind load should be averaged to each unit, and finally be distributed to each node by ANSYS software automatically.

\section{Pressure Load Fs of Lifting Rope to Arm Support}

$F s=\frac{1}{2 \times 8}\left[\left(G+\right.\right.$ Glifting group $+\frac{1}{2}$ Grope $) \times \varphi+\frac{1}{2}$ Grope $\left.\times 1.1\right]$

This pressure load should be applied to two nodes corresponding to the position where the lifting pulley at the end of jib is located in.

\section{E. Rotary Inertial Force Fh}

$$
\mathrm{Fh}=\frac{\mathrm{G} \cdot \mathrm{R}}{1000}
$$

Where $R$ - the distance from lifting position to rotary center $(\mathrm{m})$.

The functional point of rotary inertial force is not on the node. Therefore, the virtual work principle also should be applied here to distribute the force to the nodes where the nearby trolley wheels are located in equivalently. The distribution method is as same as that of calculated load of lifting capacity. 


\section{CAlCulation OF MODEl OF POLE JiB}

The calculated working conditions and corresponding parameters are determined according to GB/T 13752-92, thus working out the values necessary for model establishment. First, enter the Preprocessor Sections of ANSYS10.0 [4] to establish cross-sections of chord member, web member and draw-bar; switch to the Modeling module, and utilize the batch processing method to establish the model of jib; and then, switch to the Meshing module, and conduct meshing (including material selection, cross-section, unit pattern and mesh density) to various members, apply constraint conditions and corresponding loads; enter Solution to conduct solution; and finally enter General Postproc to set the display mode, thus displaying the output results, and analyse and discuss the correctness of results. The total number of divided units of the entire jib model is 579 .

Finite element analysis is finished for each rated lifting position of SXD50 lifting pole under working status. During working, the rated load status is lifted, the rotating is under brake status and direction of wind is perpendicular to jib. The materials of main chord of jib are all round steel of $\Phi 76 \times 5$.

Two kinds of working conditions are calculated respectively according to the designed load of lifting pole. Working condition 1: working amplitude is $20 \mathrm{~m}$, lifting load is 2.5 t. Working condition 2: working amplitude is $12.5 \mathrm{~m}$, lifting load is $4 \mathrm{t}$.

\section{CALCULATION ANALYSIS OF POLE JIB}

Working condition 1: the maximum equivalent stress by upper and lower chords is $141.538 \mathrm{Mpa}$, with the maximum displacement of $204.015 \mathrm{~mm}$. Working condition 2: the maximum equivalent stress by upper and lower chords is $151.126 \mathrm{Mpa}$, with the maximum displacement of $199.773 \mathrm{~mm}$, as shown in Figure 3 and Figure 4.

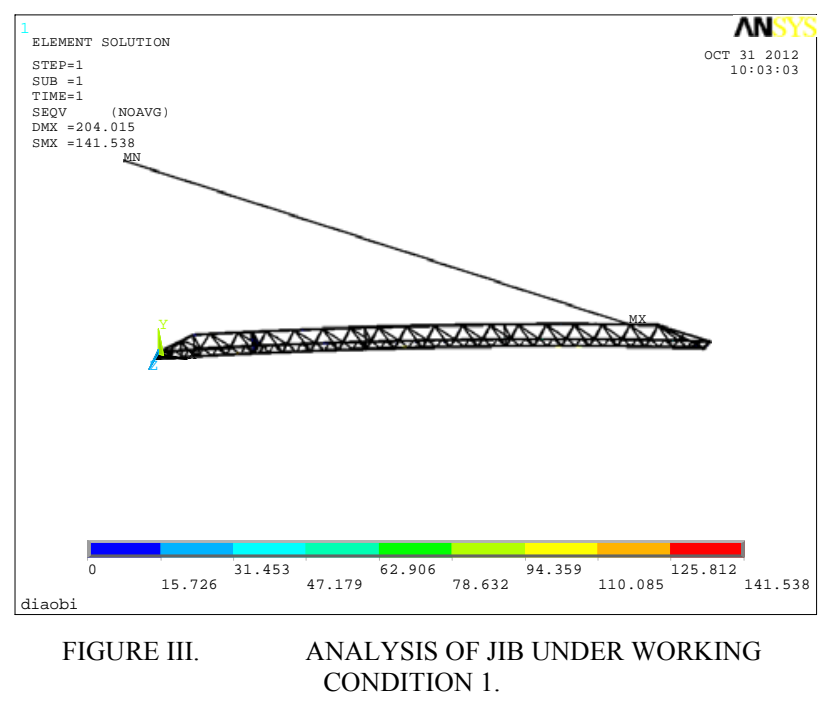

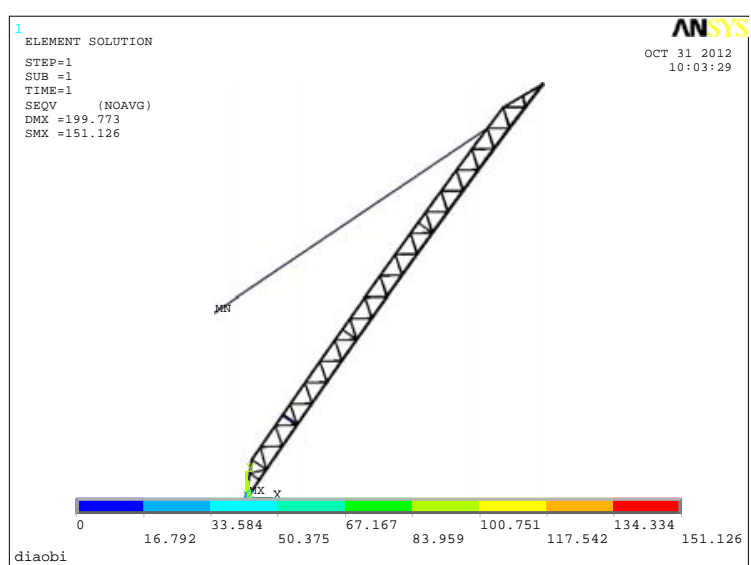

FIGURE IV. ANALYSIS OF JIB UNDER WORKING CONDITION 2.

According the stress results of these two kinds of working conditions, the equivalent stress of lower chord $\sigma_{d}=151.13 \mathrm{Mpa}$, with the maximum equivalent stress $\sigma \mathrm{dmax}=178.64 \mathrm{Mpa}$; the equivalent stress of upper chord $\sigma_{u}=119.74 \mathrm{Mpa}$, with the maximum equivalent stress $\sigma_{\text {umax }}=141.54 \mathrm{Mpa}$; the stress of web member $\sigma_{\text {tmax }}=81.6 \mathrm{Mpa}$, with $\sigma_{p \max }=96.46 \mathrm{Mpa}$; and the maximum vertical displacement $y_{\max }=204.02 \mathrm{~mm}$.

The material of upper and lower chords is Q345B, and the material of web member is $\mathrm{Q} 235 \mathrm{~B}$. The permissible stress value of $\mathrm{Q} 345 \mathrm{~B}[\sigma] \mathrm{Q} 345 \mathrm{~B}=259.40 \mathrm{Mpa}$, and the permissible stress value of Q235B $[\sigma] \mathrm{Q} 235 \mathrm{~B}=176.7 \mathrm{Mpa}$. The permissible deformation amount of jib (i.e. vertical displacement) is $2 \%$ of the arm length.

In a word, all materials and the entire structure meet the strength requirements.

\section{CONCLUSION}

Analysed the jib structure of landing-type lifting pole with single luffing jib, this thesis proposed the basic principle which the finite element model establishment of jib should comply with, and proposed corresponding methods. In this thesis, the calculated working conditions were determined and corresponding parameters were selected according to GB/T 13752-92 Design Rules for Tower Cranes, thus working out values required by model establishment. The calculation result of finite elements showed that the structural strength requirements can be met if the material of upper and lower chords of jib was Q345B and the material of web member was Q235B.

\section{REFERENCES}

[1] Q.J.Li, G.L.Lin, H.X.Liu. Application of double horizontal rotating and lifting arm grounding hold-poles in construction of large crossing towers. Guangdong Electric Power, 11, pp.72-76, 2011.

[2] Q.L.Li. Seheme Selection of Lifting poles Erection for EHV Transmission Towers. Electric Power Construction. 28(3), pp,29-22, 2007.

[3] J.Y. Ye, C.S.Huang, F.P.Duan. A structure pattern of derrick with double level arm rotating pole and application. Engineering and Construction. 3(23), pp.399-401, 2009. 
[4] J.Z.Bai, Q.Sun, Y.N.Guo, Stress-analysis of a Complex Structure with the ANASYS System, Mechanical Science and Technology. 3(22), pp.441-444, 2003. 